\title{
CINQUENTENÁRIO DO “MANUAL DE TÉCNICA DE ENFERMAGEM" (1957-2007): CONTRIBUIÇÕES NA CONSTRUÇÃO DO SABER DE ENFERMAGEM
}

\author{
Fiftieth anniversary of the "Manual de técnica de enfermagem" \\ [1975-2007]: contributions to nursing knowledge construction
Los cincuenta años del "Manual de Procedimientos de la Enfermería" (1957-2007): contribuciones a la construcción de conocimientos de la enfermería

\begin{abstract}
RESUMO
Trata-se de um estudo histórico social que tem como objetivos: descrever a trajetória da professora Elvira De Felice Souza (EFS); analisar o conteúdo do "Manual de Técnica de Enfermagem", escrito por EFS; e discutir a contribuição histórica desta obra para a bibliografia brasileira de enfermagem. 0 referencial teórico são as fases da construção do saber de enfermagem. Verificou-se que a obra de EFS veio avançar a produção bibliográfica brasileira a respeito da execução dos procedimentos técnicos de enfermagem, que à época se expressava por uma única autora brasileira. Somaram-se mais de quatro décadas desde sua utilização pelas alunas de enfermagem (1953), e, até sua última reimpressão (1995), a obra atravessou periódica atualização, chegando a ser o principal guia para a execução dos procedimentos pelas alunas de fundamentos de enfermagem, tendo sido utilizada por enfermeiros do Brasil inteiro para a elaboração de diversos manuais de enfermagem.
\end{abstract}

Palavras-chave: História da Enfermagem. Ensino. Brasil.

\begin{abstract}
This is a social historical study that aims describe professor Elvira De Felice Souza's (EFS) path; analyzing the content of "Manual de Técnica de Enfermagem" ("Nursing Technique Manual"), written by EFS; discussing the historical contribution of this work to the Brazilian nursing bibliography. The nursing knowledge construction phases are the theoretical references. It was verified that EFS's work advanced the Brazilian bibliographical production regarding the performance of technical nursing procedures, which, at that time, was expressed by a single Brazilian author. From its first use by nursing students (1953) until its last reprint (1995), more than four decades have passed. The work received periodic updating, being the main procedures performance guide for by nursing foundations students, being used by nurses throughout Brazil in order to elaborate several nursing manuals.
\end{abstract}

Keywords: History of Nursing. Teaching. Brazil.

\section{Resumen}

Es es un estudio histórico y social, que tiene como objetivos: describir la trayectoria de la profesora Elvira De Felice Souza (EFS); analizar el contenido del "Manual de Procedimientos de la Enfermería", escrito por EFS; discutir la contribución histórica de este trabajo a la bibliografia brasileña del área de enfermería. El referencial teórico está constituído por las etapas de construcción de conocimientos de enfermería. Se constató que la obra de EFS ayudó al avance de la producción bibliográfica brasileña en relación a la ejecución de los procedimientos técnicos de enfermería, que en la época estaban expresados por una única autora brasileña. Pasaron más de cuatro décadas desde su uso por las estudiantes de enfermería (1953) hasta su última reimpresión (1995), recibiendo periódica actualización, y llegar a ser un guía principal para la aplicación de procedimientos por las estudiantes de fundamentos de enfermería, y fue utilizado por las enfermeras en Brasil para el diseño de diversos manuales de enfermería.

Palabras clave: Historia de la Enfermería. Enseñanza. Brasil.

${ }^{1}$ Acadêmica do $8^{\circ}$ período do curso de graduação da EEAN/ UFRJ; bolsista PIBIC; membro do Nuphebras. Brasil. E-mail: ivecristina@ig.com.br, ²Doutora em História da Enfermagem. Professora do quadro permanente do programa de Pós-graduação da EEAN/UFRJ. Membro Fundador do Nuphebras. Pesquisadora 1A do CNPq. Brasil. E-mail: iedabarreira@openlink.com.br, ${ }^{3}$ Doutora em História da Enfermagem. Professora visitante da Faculdade de Enfermagem da UERJ. Membro fundador do Nuphebras. Pesquisadora do CNPq. Brasil. E-mail: suelybaptista@openlink.com.br 
Cinquentenário do "Manual de Técnica de Enfermagem" e

contribuições para a Enfermagem

Lucena ICD, Barreira IA, Baptista SS

\section{INTRODUCÃO}

0 presente trabalho tem como objeto de estudo o livro de autoria da enfermeira Elvira De Felice Souza, intitulado "Manual de Técnica de Enfermagem", publicado pela primeira vez em 1957 e que mereceu várias reedições, face à sua relevância para o ensino e a prática de enfermagem no Brasil.

Elvira De Felice Souza (EFS) formou-se enfermeira na então Escola Ana Néri, da Universidade do Brasil, hoje Escola de Enfermagem Anna Nery, da Universidade Federal do Rio de Janeiro (EEAN/UFRJ). Como diplomada, construiu uma dedicada e extensa carreira docente, ministrou disciplinas de graduação e pós-graduação. Na EEAN, lecionou os Fundamentos da Enfermagem durante 27 anos, abrangendo mais de cinquenta turmas do curso de graduação. Foi diretora da Escola Anna Nery de 1971 a 1975. Entre as inúmeras contribuições de EFS na área acadêmica e na vida associativa resulta a autoria dos livros: Administração de medicamentos e preparo de soluções, de 1955; e o que alcançou maior repercussão, sendo adotado como livro-texto em todas as Escolas de Enfermagem do Brasil: "Manual de Técnica de Enfermagem".

Desde a criação da EEAN, em 1923 (então denominada Escola de Enfermeiras no Departamento Nacional de Saúde Pública), ${ }^{1}$ a enfermagem norte-americana forneceu os padrões ideais a serem aqui implantados, tanto pela presença de enfermeiras americanas como pela realização de cursos de pós-graduação pelas enfermeiras diplomadas brasileiras nos Estados Unidos da América (EUA), e ainda pela tradução de literatura norte-americana de enfermagem. A prática da enfermagem hospitalar apresentava características herdadas do "taylorismo", como a divisão do trabalho e a valorização do "como fazer", especificados em manuais de normas, rotinas e procedimentos técnicos. ${ }^{2}{ }^{3}$

À época do lançamento da primeira edição do Manual, a cidade do Rio de Janeiro vivia seus "anos dourados", do nacional desenvolvimentismo do governo Juscelino Kubitschek. Juntamente com a ampliação do parque industrial e do crescimento da população urbana, verificou-se neste período uma proliferação da rede hospitalar, abrindo novos espaços para a atuação da enfermagem e criando a necessidade de maiores contingentes de pessoal com preparo específico para trabalhar nos seus serviços. ${ }^{3}$

No campo da educação dava-se o debate em torno da escolaridade das candidatas às escolas de enfermagem, questão só resolvida em 1961, com a primeira Lei de Diretrizes e Bases da Educação Nacional, que teve importantes repercussões para uma inserção mais adequada da enfermagem no nível superior de ensino, pela exigência do curso secundário completo. $^{5}$

No que se refere à publicação de obras de enfermagem no Brasil, o primeiro livro escrito por uma enfermeira brasileira sobre fundamentos de enfermagem foi "Técnica de
Enfermagem" (1933), por Zaira Cintra Vidal, professora da Escola Anna Nery, ${ }^{5}$ que também escreveu "Drogas e Soluções", de 1934, e "Manual de Enfermeira: Técnica de Atadura", de 1948. Em 1955, ocorreu a publicação do livro "Administração de Medicamentos e Preparo de Soluções", da própria EFS, que após dois anos publicou o "Manual de Técnica de Enfermagem", que se constituiu, portanto, a quinta obra brasileira publicada sobre fundamentos de enfermagem.

Pretende-se neste estudo atender aos seguintes objetivos: descrever a trajetória da Professora Elvira De Felice Souza; analisar o conteúdo do "Manual de Técnica de Enfermagem", escrito por EFS; e discutir a contribuição histórica desta obra para a bibliografia brasileira de enfermagem.

\section{ABORDAGEM TEÓRICA}

Trata-se de um estudo de natureza histórico-social. Utilizaram-se como referência para a análise do livro "Manual de Técnica de Enfermagem" as fases da construção do saber de enfermagem, segundo Almeida e Rocha na obra "OSaber de Enfermagem e sua Dimensão Prática", 1986.

Almeida e Rocha têm como objeto o processo de construção do saber de enfermagem, colocado em uma perspectiva histórica. Para tal, utilizam três tipos de saber ${ }^{7}$, que juntos julgam representar quase a totalidade do saber da prática de enfermagem, como se segue:

\section{1) As técnicas de enfermagem}

Representam a primeira expressão do saber de enfermagem. Apesar de as técnicas de enfermagem, ou arte de enfermagem, como eram denominadas, sempre tivessem estado presentes nos cuidados de enfermagem, seu surgimento como estrutura do saber ocorreu no início do século XX, nos Estados Unidos da América do Norte. Os manuais de técnica apresentam a descrição dos procedimentos a serem executados, passo a passo, e especificam também a relação do material a ser usado. Com o tempo, à descrição das técnicas acrescenta-se a razão de ser de tais procedimentos, com a busca de fundamentação em outras áreas do conhecimento. Esta fase tem seu desenvolvimento pleno nas décadas de 30, 40 e 50.

Os autores caracterizam esta fase do saber de enfermagem como o momento em que o objeto da enfermagem não estava centrado no cuidado do paciente, mas na maneira de executar as tarefas.

\section{2) Os princípios científicos}

$\mathrm{Na}$ década de 50 , buscando uma maior autonomia no exercício da profissão, os enfermeiros passam a procurar uma fundamentação científica para a sua prática, com base principalmente nas ciências naturais (anatomia, microbiologia, fisiologia, patologia) e também nas ciências sociais. Almeida e Rocha afirmam que nesta época "o saber de enfermagem, ao mesmo tempo em que quer se tornar científico, procura essa cientificidade na aproximação com o saber da medicina.(...)"(p. 61) 
Um aspecto importante enfatizado pelos autores é o fato de que "o saber expresso pelos princípios científicos, que predominou principalmente nas décadas de 50 e 60, é também visto pela liderança da enfermagem como dependente, sem possuir uma natureza específica e sem ser autônomo" (p.87).

\section{3) As teorias de enfermagem}

Surgem a partir da procura da autonomia e da especificidade do saber de enfermagem, no final da década de 60 , por enfermeiras norte-americanas, como Virgínia Henderson, e no Brasil, na década de 70, tendo como autora principal Wanda de Aguiar Horta. Constituem a expressão mais recente e dominante do saber na enfermagem ocidental, cujo conteúdo permite observar como a enfermagem é focada na atualidade. As teorias de enfermagem, de acordo com a literatura, se propõem a construir um corpo de conhecimentos específicos da enfermagem e conferir-lhe, desta maneira, um estatuto de ciência.

Até a década de 60 , quando predominava o modelo dos princípios científicos, os conhecimentos predominantes são trazidos da biologia, da fisiologia, da medicina, etc. Observase uma substituição de fontes de conhecimento a partir de então, em que se privilegia a área da psicologia, com ênfase nos aspectos comportamentais e das relações humanas.

\section{METODOLOGIA}

A localização de exemplares das seis edições da obra em estudo ofereceu dificuldades inesperadas: somente exemplares da quinta e da sexta edição do "Manual de Técnica de Enfermagem" se encontravam nas estantes da biblioteca setorial da EEAN.

A segunda edição do livro, de 1959, nos foi cedida pela Escola de Enfermagem Wenceslau Braz, de Itajubá, MG, graças à preciosa ajuda da professora Waldere Fabri. A primeira edição, publicada pela Universidade do Brasil em 1957, existe apenas na forma mimeografada, e, após um ano de procura, foi localizado um exemplar na biblioteca da EEUFRS, com a valiosa intermediação da professora Maria Henriqueta L. Kruse. Na mesma semana em que houve este contato, a bibliotecária da EEAN nos deu acesso a uma caixa de livros antigos, entre os quais se encontravam a primeira, a terceira e a quarta edição do "Manual de Técnica de Enfermagem".

Utilizamos, assim, as seguintes fontes primárias: as seis edições do livro "Manual de Técnica de Enfermagem", de Elvira De Felice Souza: depoimento oral concedido pela professora emérita Elvira De Felice Souza à professora Suely Baptista, juntamente com as bolsistas de iniciação científica lve Lucena e Raquel Maciel, em março de 2007; depoimento oral das exalunas da EEAN Maria da Luz Gomes e Maria Bernadete Bandeira, à bolsista Ive Lucena em julho e outubro de 2007; 0 documentário "Livros de Enfermagem-Brasil (1916/1988)", organizado por leda Barreira e Castro e Suely de Souza Baptista, assim como alguns manuais de técnica apontados no documentário, escritos por enfermeiras brasileiras e publicados nas décadas de 60,70 e 80, bem como documentos escritos, orais e iconográficos do Centro de Documentação da EEAN/ UFRJ, a exemplo do histórico escolar de EFS.

Como fontes secundárias, utilizamos artigos, livros e teses sobre os seguintes temas: metodologia científica; saberes e práticas; procedimentos técnicos e tecnologia; enfermagem fundamental; ensino superior de enfermagem.

Os instrumentos utilizados foram os quadros para a classificação dos dados, roteiros de entrevista e gravador digital. Os procedimentos de coleta foram a consulta às fontes escritas, bem como a realização de entrevistas na residência das entrevistadas ou no pavilhão de aulas da EEAN. Os procedimentos de análise e interpretação dos dados foram realizados por meio da classificação, categorização, contextualização e triangulação dos dados oriundos de diversas fontes. Foi feita uma análise comparativa das seis edições quanto ao ano, título, editora, número de páginas, formato, número de unidades e reimpressões, e ainda uma comparação entre a primeira e a sexta edições, quanto ao conteúdo. Para essa comparação, consideramos as páginas dedicadas ao ensino das técnicas, como relacionadas ao saber das técnicas de enfermagem; as páginas que enfocaram conhecimentos advindos de outras áreas (biologia, fisiologia, medicina, etc.), como representantes do saber relacionado aos princípios científicos; $e$ as páginas onde predomina o conhecimento próprio da enfermagem (aspectos legais; definição de enfermagem; plano de cuidados; conhecimentos predominantemente adquiridos da área da psicologia, com ênfase nos aspectos comportamentais e das relações humanas), como representantes do saber relacionado às teorias de enfermagem.

Os aspectos éticos da pesquisa com seres humanos foram respeitados, conforme Resolução n. 196/96 do Conselho Nacional de Saúde. Foi elaborado o Termo de Consentimento Livre e Esclarecido, além do Termo de Doação de Depoimento, cedido pelas entrevistadas ao Centro de Documentação da EEAN (CEDOC). 0 estudo foi aprovado pelo Comitê de Ética da Escola de Enfermagem Anna Nery, em novembro de 2007.

\section{RESULTADOS}

\section{A trajetória profissional de Elvira De Felice Souza}

Elvira De Felice Souza, filha de Jacintho De Felice e de Thereza Bragassa, nasceu em 27 de junho de 1920, na cidade de São Paulo. 0 casal teve quatro filhas, duas das quais faleceram ainda na juventude. Educada com as irmãs no rigor da cultura italiana, desde cedo Elvira cultivou seus dotes para o canto lírico. Fez o curso secundário na Escola São Vicente de Paulo, em São Paulo. Terminando em 1940, continuou morando com os pais, ocupando-se em costurar em casa para pessoas amigas, enquanto cultivava o desejo de ser normalista.

Quando estava se preparando para ingressar na Escola Normal, com o incentivo de uma amiga carioca, que não a via "nem como normalista nem costureira, e sim como enfermeira", 
Cinquentenário do "Manual de Técnica de Enfermagem" e contribuições para a Enfermagem

a jovem Elvira veio para a Escola Ana Néri, sendo afetuosamente recebida pela então diretora Laís Netto dos Reys. À chegada de Elvira, a diretora fez questão que também sua irmã mais velha, Josefina, que veio ao Rio de Janeiro para acompanhá-la, dormisse na Escola: "No dia seguinte, então, minha irmã ficou, continuou a ficar lá, usava o piano, a biblioteca, ela ficava lá, rodava como se estivesse na sua casa" $8: 3$.

Uma vez aprovada nos exames de conhecimentos e na entrevista de seleção com a diretora Laís Netto dos Reys e com a chefe da divisão de ensino Olga Lacorte, iniciou o curso em 3 de junho de 1942, então com 22 anos de idade. Acostumada à educação rígida dos pais, Elvira De Felice adaptou-se bem ao regime disciplinar da escola, e a identificação com a profissão logo se manifestou: "Eu me sentia maravilhosamente bem, nunca pensei que pudesse gostar tanto, porque eu vim saber o que era enfermagem quando entrei na Escola." 8:5.

Aluna inteligente e aplicada, concluiu o curso em 19 de junho de 1945. 0 desejo de permanecer no Rio de Janeiro de modo a continuar o namoro iniciado em um baile de formatura da escola foi viabilizado pelo convite feito pela diretora em 1946 para que lecionasse a disciplina Arte de Enfermagem, mais tarde Fundamentos de Enfermagem. Inicia-se assim uma carreira docente que muito acrescentou à EEAN, e à enfermagem brasileira.

Além de "Fundamentos de Enfermagem" (ex-Arte de Enfermagem), disciplina que lecionou por 27 anos (19461973), Elvira De Felice Souza lecionou também outras

\section{O “Manual de Técnica de Enfermagem"}

No último ano do curso de enfermagem, em 1945, EFS iniciou a elaboração do futuro "Manual de Técnica de Enfermagem", com o propósito de oferecer às alunas um guia para a correta execução dos procedimentos de enfermagem.

0 livro foi pela primeira vez compilado e mimeografado em 1948. Seu êxito entre as enfermeiras de todo o Brasil o levou a ser apresentado em forma gráfica mais apurada, sendo então lançado pela Oficina Gráfica da Universidade do Brasil em 1957, ainda em formato mimeografado.

Apesar de a elaboração do Manual ter se iniciado em 1945, o primeiro livro a ser publicado por EFS foi "Administração de disciplinas, como consta em seu histórico de vida escolar: "Drogas e Soluções" (1946-1971); "Higiene" (1946-1950); "Ataduras" (1948-1969) e "Revisão de Técnica de Enfermagem" (1948-1962).

No período de 1947 a 1949, ela fez um curso sobre Ensino de Enfermagem na Escola Ana Néri. De setembro de 1951 a setembro de 1952, com bolsa da Fundação Kellogg, realizou curso de pós-graduação na Syracuse University, no estado de Nova lorque, EUA, o que mais tarde lhe valeu o credenciamento para atuar nos cursos de pós-graduação.

Os cargos administrativos por ela ocupados na UFRJ incluem a chefia da Maternidade Escola, de 1947 a 1951; a vice-direção da EEAN, de 1967 a 1971; a direção da Escola, de 1971 a 1975. Dentre os inúmeros trabalhos por ela realizados, merecem destaque sua participação no "Estudo sobre o Problema da Lotação de Pessoal Docente da EEAN", publicado na Revista Brasileira de Enfermagem em 1970, bem como a publicação de artigos na Revista Brasileira de Enfermagem sobre as técnicas de Enfermagem, de 1949 a 1955.

Como atividade de extensão, podemos mencionar o Curso Enfermagem no Lar, levado ao ar no Programa Edna Savaget, da TV Globo, de 1965 a 1966, e na TV Tupi, de 1966 a 1970.

Quando aposentada, foi agraciada com o título de professora emérita da UFRJ. EFS, atualmente com 88 anos, é viúva e reside em apartamento na zona sul do Rio de Janeiro, participando de encontros com ex-alunas e de comemorações na EEAN.

Medicamentos e Preparo de Soluções" (1955). Neste, quando a autora descreve as técnicas de administração de medicamentos, ela se refere ao "Manual de Técnica de Enfermagem", (ou "Manual de Arte de Enfermagem", como é citado algumas vezes), edição de 1953, apontando o número da página respectiva, o que evidencia que, à época, o "Manual de Técnica de Enfermagem" já era bastante conhecido no meio acadêmico.

0 Quadro 1 apresenta as características das seis edições do livro "Manual de Técnica", quanto ao ano, título, editora, reimpressões, número de páginas e unidades

Quadro 1. Caracterização das seis edições do livro "Manual de Técnica de Enfermagem" quanto ao ano, título, editora, número de páginas, formato, número de unidades e de reimpressões.

\begin{tabular}{|c|c|c|c|c|c|c|c|}
\hline Ed. & Ano & Título & Editor & $\begin{array}{c}\text { No. } \\
\text { de } \\
\text { págs }\end{array}$ & Formato & $\begin{array}{l}\text { No. de } \\
\text { unidades }\end{array}$ & Reimpressões \\
\hline $1^{a}$ & 1957 & $\begin{array}{l}\text { "Manual de } \\
\text { técnica de } \\
\text { enfermagem" }\end{array}$ & $\begin{array}{l}\text { Universidade } \\
\text { do Brasil }\end{array}$ & 174 & $32 \mathrm{~cm}$ & 7 & Não \\
\hline $2^{\mathrm{a}}$ & 1959 & $\begin{array}{l}\text { "Manual de } \\
\text { técnica de } \\
\text { enfermagem" }\end{array}$ & $\begin{array}{c}\text { Bruno } \\
\text { Buccini }\end{array}$ & 195 & $26,5 \mathrm{~cm}$ & 7 & Não \\
\hline $3^{a}$ & 1962 & $\begin{array}{l}\text { "Manual de } \\
\text { técnica de } \\
\text { enfermagem" }\end{array}$ & $\begin{array}{c}\text { Bruno } \\
\text { Buccini }\end{array}$ & 213 & $26,5 \mathrm{~cm}$ & 7 & Não \\
\hline $4^{a}$ & 1966 & $\begin{array}{l}\text { "Nôvo Manual } \\
\text { de Técnica de } \\
\text { Enfermagem" }\end{array}$ & $\begin{array}{l}\text { Bruno } \\
\text { Buccini }\end{array}$ & 304 & $23 \mathrm{~cm}$ & 7 & Não \\
\hline $5^{\mathrm{a}}$ & 1972 & $\begin{array}{c}\text { "Nôvo Manual } \\
\text { de } \\
\text { Enfermagem" }\end{array}$ & $\begin{array}{l}\text { Bruno } \\
\text { Buccini }\end{array}$ & 496 & $21 \mathrm{~cm}$ & 21 & Não \\
\hline $6^{\mathrm{a}}$ & 1976 & $\begin{array}{c}\text { "Novo Manual } \\
\text { de } \\
\text { Enfermagem" }\end{array}$ & $\begin{array}{l}\text { Cultura } \\
\text { Médica }\end{array}$ & 491 & $21 \mathrm{~cm}$ & 21 & 27 \\
\hline
\end{tabular}


Tomando-se por base a primeira (1957) e a sexta (1976) edições do livro, aspectos importantes devem ser destacados. Em relação à primeira unidade do livro, na primeira edição, a autora apresenta temas diretamente relacionados à profissão, como o valor da saúde, o que é enfermagem, e o hospital (funç̃̃es, classificação, organização), e passa ao item "Introdução à Técnica de Enfermagem", em que a palavra TÉCNICA é descrita como:

(...) o conjunto dos processos de uma Arte. Mas não tôda a Arte. Esta supõe uma inspiração, um ideal e aptidões capazes de uma realização à qual o artista imprime o cunho de sua personalidade. ${ }^{9: 7}$

A seguir, a autora prossegue apresentando as Condições gerais para a boa execução técnica, segundo os princípios gerais de segurança, conforto e economia. Quanto à segurança, se refere, por exemplo, a evitar contaminação, evitar resfriados, prevenir acidentes. 0 "conforto" se refere, por exemplo, a manter o silêncio nas enfermarias, evitar ruídos desnecessários. A economia se refere ao tempo de execução, ao "esforço" despendido e ao material utilizado, por exemplo, evitar movimentos desnecessários, conservar o material limpo e arrumado.

No entanto, como o Manual foi sendo permanentemente revisto, recebendo periódica atualização, feita pela autora, com a colaboração de diversas professoras da EAN, como Cecília Pecego Coelho e Vivina Lanzarini de Carvalho, seu conteúdo foi sendo progressivamente enriquecido. Assim, ao compararmos a primeira e a sexta edições, verificamos que, na sexta edição, a palavra "Técnica" é por vezes substituída por "Enfermagem", como na primeira unidade, que se inicia com a definição do conceito de enfermagem, segundo Irmã Olívia, da Universidade Católica dos Estados Unidos da América. "Enfermagem, no seu sentido lato, é uma arte e uma ciência, que visa o paciente como um todo - corpo, mente e espírito (...) "10:7

No subtítulo "Condições gerais para Boa execução de Enfermagem", quanto à segurança, ao conforto, à economia, observa-se que os tópicos são iguais aos apresentados na primeira edição e os exemplos são os mesmos. Porém, no subtítulo, a palavra "Técnica foi substituída pela palavra "Enfermagem".

Quanto à distribuição dos conteúdos pelas páginas da obra, comparando-se a primeira (1957) com a sexta edição (1976), verifica-se que das 168 páginas analisadas na primeira edição, cerca de $80 \%$ (135:168) são dedicadas às técnicas de enfermagem, enquanto os outros $20 \%$ (33:168) contêm informações advindas de outras áreas do conhecimento (biologia, física, química, etc.) que explicam o porquê da realização das técnicas. Não foram encontradas nesta edição páginas representativas do saber relacionado às teorias de enfermagem.

Já nas 458 páginas analisadas na sexta edição, percebe-se que há ainda o predomínio de páginas dedicadas às técnicas, porém, com bem menor porcentagem, ou seja, cerca de $46 \%$ (211:458). São dedicadas em torno de $42 \%$ das páginas (193:458) aos princípios científicos que embasam as técnicas de enfermagem, enquanto $12 \%$ das páginas (54:458) apresentam as bases teóricas da enfermagem.

Quanto à explanação das técnicas de enfermagem, as seis edições do Manual apresentam o mesmo modelo, contendo os tópicos:

- Finalidades: apresenta os resultados esperados da realização da técnica, organizados por tópicos.

- Material necessário: iniciado pela expressão "Bandeja contendo", seguido dos itens enumerados.

- Material acessório: também referido algumas vezes como "Material extra", é o material que complementa a boa execução da técnica. Por exemplo, biombos, suporte de soro.

- Método: é a descrição dos passos da técnica, segundo uma sequência lógica, iniciando-se cada frase com os verbos no infinitivo, como "preparar", "lubrificar", "retirar".

- Pontos a observar: este tópico apresenta as precauções a serem tomadas inerentes aos princípios de segurança, conforto e economia.

\section{A contribuição do "Manual de Técnica de Enfermagem" para a bibliografia brasileira de enfermagem}

Até meados do século $X X$, os livros existentes sobre fundamentos de enfermagem escritos por enfermeiras brasileiras eram poucos, merecendo destaque os livros da enfermeira Zaira Cintra Vidal, a saber: Técnica de Enfermagem, de 1933, Drogas e Soluções, de 1934, e Manual de Enfermeira: Técnica de Atadura, de 1948.

Em depoimento, a professora EFS declarou que, para a elaboração do seu "Manual de Técnica de Enfermagem", ela se baseou nos conhecimentos adquiridos no curso de enfermagem, em livros de enfermagem norte-americanos e, principalmente, em sua experiência docente, deixando de mencionar qualquer livro de enfermagem brasileiro.

$\mathrm{Na}$ EEAN, o livro da professora Elvira passa a ser o único guia de execução das técnicas pelas alunas à época. Para as enfermeiras formadas pela EEAN em 1963, Maria Bernadete Bandeira e Maria da Luz Gomes, que tiveram a autora do livro como professora de fundamentos, a maneira como Ihes foram por ela ensinadas as técnicas de enfermagem permitiu que os movimentos de cada passo do procedimento técnico fossem incorporados de forma automática na sua vida profissional. Segundo elas, as enfermeiras diplomadas à época eram muito bem preparadas, não só para a assistência, mas também para a docência. ${ }^{11,12}$

Outro ponto a destacar é o de que, a partir da década de 60, o manual de autoria de EFS começa a ser citado em suas diversas edições. Citamos os seguintes exemplos: a segunda edição é citada pela enfermeira Maria Luiza de Souza (et alli) no "Manual de Enfermagem da ICOMI" (1963); a quinta edição 
Cinquentenário do "Manual de Técnica de Enfermagem" e contribuições para a Enfermagem

é citada pela enfermeira Edilburga Pereira em "Moderna Técnica de Enfermagem" (1973); e a sexta edição é citada, no Rio de Janeiro, pela enfermeira Maria José Bezerra de Araújo no livro "Técnicas Fundamentais de Enfermagem" (1983) e, em São Paulo, por Mara Sordi e Maria Aparecida Nunes em seu "Manual Básico de Enfermagem" (1988).

$\mathrm{Na}$ EEAN, no final da década de 70, ocorreu a mudança do principal campo de estágio, do Hospital Escola São Francisco de Assis (HESFA) para o Hospital Universitário Clementino Fraga Filho (HUCFF), cuja organização e funcionamento atendiam a uma lógica própria, com a adoção de novas técnicas, normas e rotinas de enfermagem, inclusive com a elaboração de um manual de técnica, intitulado "Manual de Procedimentos Técnicos da Divisão de Enfermagem (DEN)". ${ }^{13}$ Além disso, a reforma curricular do curso de graduação, que determinou a implantação de um novo currículo pleno, a partir de 1978, segundo os princípios de integração curricular, teve como uma de suas consequências a eliminação da disciplina Fundamentos de Enfermagem. ${ }^{14}$ Estes fatores determinaram uma diminuição progressiva da utilização do "Manual de Técnica de Enfermagem", de EFS, por docentes e alunos e a percepção da autora de que o reconhecimento de seu livro terminou sendo maior em outras escolas do que na própria EEAN.

Porém, vale destacar que a última edição do livro de EFS (1976) recebeu 27 reimpressões, sendo a última realizada em 1995. Tal fato evidencia a grande repercussão que o 'Manual de Técnica de Enfermagem" obteve entre alunos e profissionais e a importância que deve ser atribuída ao mesmo pela contribuição dada à bibliografia brasileira de enfermagem.

\section{CONCLUSÃO}

A obra de Elvira De Felice Souza "Manual de Técnica de Enfermagem" representa uma importante contribuição à bibliografia brasileira de enfermagem, no que diz respeito à execução dos procedimentos técnicos, uma vez que, à época do seu lançamento, havia apenas uma outra autora brasileira que escrevera sobre o assunto.

Além disso, esta obra, que começou a ser utilizada pelas alunas de enfermagem antes mesmo de sua publicação, em 1953 (quando é citada no livro "Administração de Medicamentos e Preparo de Soluções"), teve sua última reimpressão em 1995, somando-se, portanto, mais de quatro décadas de vida útil.

Assim, o "Manual de Técnica de Enfermagem" atravessou as três fases do saber de enfermagem descritas por Almeida e Rocha. Apesar de o "Manual de Técnicas de Enfermagem" se constituir em uma obra predominantemente voltada para os procedimentos técnicos, ao longo do tempo, a autora buscou outros saberes para a composição do livro, tendo a eles associado progressivamente os princípios científicos pertinentes.

Adotado como livro-texto nas escolas de enfermagem brasileiras, chegou a se constituir como principal guia para a execução dos procedimentos de enfermagem. Por outro lado, sua utilização foi de grande importância para a elaboração de diversos manuais de enfermagem, por enfermeiros de todo 0 Brasil.

Na década de 70, o "Manual de Técnica de Enfermagem" passa a ter menor impacto no meio acadêmico. Não obstante, atualmente nota-se que os livros passo-a-passo são uma tendência no mercado editorial, o que reflete uma valorização da execução adequada dos procedimentos técnicos, de forma a obedecer aos princípios de conforto, segurança e economia

\section{REFERÊNCIAS}

1. Baptista SS. A luta por um espaço na universidade: o caso da Escola de Enfermagem Anna Nery. [tese de doutorado] Rio de Janeiro (RJ): Escola de Enfermagem Anna Nery /UFRJ; 1995.

2. Bellato R, Pasti MJ, Takeda E. Algumas reflexões sobre o método funcional no trabalho da enfermagem. Rev Latino-am Enfermagem [on-line] 1997 jan; [citado 26 jul 2007] 5 (1). Disponivel em: http:// www.scielo.br/scielo.php

3. Dantas RAS, Aguillar OM. 0 ensino médio e o exercício profissional no contexto da enfermagem brasileira. Rev Latino-am Enfermagem [on-line] 1999 abr; [citado 22 jul 2007]; 7 (2). Disponível em: http:/ wwww.scielo.br/scielo.php

4. Moura G. Tio Sam chega ao Brasil: a penetração cultural americana. $6^{a}$ ed. São Paulo (SP): Brasiliense; 1984.

5. Baptista SS, Barreira IA. A enfermagem na universidade brasileira: buscando espaços, conquistando posições. Esc Anna Nery Rev Enferm $2000 \mathrm{abr} ; 4$ (1): 21-30

6. Lopes GT, Caldas NP, Lima TCS, Martingil IC. A vida e a obra de Zaíra Cintra Vidal. Rev Bras Enferm 2001 abr/jun; 54 (2): 149-392.

7. Almeida MCP, Rocha JSY. 0 saber de enfermagem e sua dimensão prática. São Paulo (SP): Cortez; 1986.

8. Souza EF. Entrevista concedida à Suely Baptista em 2007 na cidade do Rio de Janeiro. [2 cassetes sonoros] Rio de Janeiro (RJ): UFRJ/ EEAN/ Centro de Documentação; 2009

9. Souza EF. Manual de técnica de enfermagem. Rio de Janeiro (RJ): Bruno Buccini; 1957.

10. Souza EF. Novo manual de enfermagem: procedimentos e cuidados básicos. $6^{\text {a }}$ ed. Rio de Janeiro (RJ): Cultura Médica; 1988

11. Gomes ML. Entrevista concedida a Ive Lucena em 2007 na cidade do Rio de Janeiro. [CD-ROM]. Rio de Janeiro (RJ): UFRJ/EEAN/Centro de Documentação; 2009

12. Bandeira MB. Entrevista concedida a Ive Lucena em 2007 na cidade do Rio de Janeiro. [CD-ROM]. Rio de Janeiro (RJ): UFRJ/ EEAN/ Centro de Documentação; 2009

13. Macedo ICS. Retrospecto da prática da enfermagem hospitalar: construção de um novo caminho para a participação da equipe de enfermagem. [tese de livre docência]: Rio de Janeiro (RJ): Universidade do Rio de Janeiro; 1990.

14. Carvalho V, Castro IB. Marco conceitual para o ensino e a pesquisa de enfermagem fundamental: um ponto de vista. Rev Bras Enferm $1985 \mathrm{jan} / \mathrm{mar} ; 38$ (1): 76-86. 